\title{
消防用ノズルにおける静圧計測によるノズル圧力の推定
}

仲村 公孝*1，小原 弘道*2

\section{Estimate of nozzle pressure for firefighting nozzles from static pressure measurement}

\author{
Kimitaka NAKAMURA ${ }^{* 1}$ and Hiromichi OBARA ${ }^{* 2}$ \\ ${ }^{*}$ SAKURA RUBBER CO., LTD \\ 1-21-17 Sasazuka, Shibuya-ku, Tokyo 151-8587, Japan \\ ${ }^{2}$ Department of Mechanical Engineering, Tokyo Metropolitan University \\ 1-1 Minamiosawa, Hachiouji-shi, Tokyo 192-0397, Japan
}

Received: 20 April 2019; Revised: 29 May 2019; Accepted: 10 July 2019

\begin{abstract}
Performance evaluations of a firefighting pump are important for inspection of fire equipment. A standard protocol established by the Ministry of Internal Affairs and Communications is generally employed to measure the firefighting pump performance using the static pressure of a standard straightening pipe to calculate a nozzle pressure without any direct measurements at the core of the jet of the firefighting nozzle. This standard protocol is a convenient method to evaluate nozzle pressure using the standard firefighting nozzle designed for the standard straightening pipe which has diameter $65 \mathrm{~mm}$. In late years, there are some opportunities for a large-capacity firefighting pump performance evaluations using a large diameter straightening pipe (75 mm). However, it is not applicable to the straightening pipe ( $75 \mathrm{~mm}$ ), because the protocol is based on the empirical table for $65 \mathrm{~mm}$ pipe. In this study, a new estimated expression was devised for the nozzle pressure to evaluate for performance of the large-capacity firefighting pump. Empirical standard protocol, experimental value and ideal value calculated by Bernoulli's theorem were compared and discussed. Results was shown that the estimated expression was expansion of the empirical standard protocol and the validity was shown. By comparison with experimental values, the estimated expression was proven to be applicable to flow straightening pipe diameter $75 \mathrm{~mm}$.
\end{abstract}

Keywords : Nozzle, High Reynolds number, Jet, Straightening pipe

\section{1. 緒言}

消防ポンプ自動車に搭載されている動力消防ポンプは，国の定める省令(総務省，2013)にしたがい，放水性能により 等級付けがされている. なかでも最大等級である A-1 級の規格放水量は， $2800 \mathrm{~L} / \mathrm{min}$ 以上と規定されているが，近年 さらなる大容量の放水性能が求められている. 1995 年の阪神・淡路大震災の教訓から, 遠距離送水が可能なシステムと して, 送水能力 $4000 \mathrm{~L} / \mathrm{min}$, 送水距離 $1.8 \mathrm{~km}$ の海水利用型消防水利システムが全国に配備された(総務省消防庁, 2011). 2003 年 9 月 26 日には，北海道十勝沖を震源とする M8.0 の地震により，製油所の屋外タンク火災が発生し，約 44 時間 燃え続けた. これを受け全国の石油等を貯蔵取扱する事業所に, $10000 \mathrm{~L} / \mathrm{min}$ 以上の放水能力を持つ「大容量泡放射シ ステム」を設置する法改正がなされた(川田，2007). また 2011 年の東日本大震災による福島第一原子力発電所の事故を 受け，全電源喪失時の代替注水機能の確保のため，各原子力発電所に 5000 ～ $20000 \mathrm{~L} / \mathrm{min}$ 級のポンプ車が導入されて いる. このように動力消防ポンプにおける放水量の大容量化の必要性が高まっている.

動力消防ポンプの大容量化が求められるなか，国の定める省令に基づく性能評価において，その放水性能は放水口に おける放水静圧力（以下「静圧」）および放水量（以下「流量」）との組み合わせにより規定されている．動力消防ポン プの放水口に整流筒と呼ばれる筒状の直状管を取付け，その先にテーパ状の管槍および放水口径を定めるノズルを取付 ける (図 1). 静圧は整流筒から垂直に立ち上げられた圧力計で計測 (ゲージ圧) する.消防ポンプ自動車の受託試験細 則(日本消防検定協会，2011)によれば，流量をノズル口径およびノズル圧力により算出する場合はピトー管を使用し， ピト一管の先端をノズル中心線上におけるノズル出口からノズル口径の2分の1の距離の位置で計測した全圧（ゲージ 圧）をノズル圧力とする. ノズル口径を $d_{1} \mathrm{~mm}$ ，ノズル圧力を $P_{N} \mathrm{MPa}$ とすれば，流量 $Q \mathrm{~L} / \mathrm{min}$ は次式で算出される.

\footnotetext{
No.19-00153 [DOI:10.1299/transjsme.19-00153], J-STAGE Advance Publication date : 19 July, 2019

*1 櫻護謨 (株) （干151-8587 東京都渋谷区笹塚 1-21-17）

*2 正員, 首都大学東京 大学院（干192-0397 東京都八王子市南大沢 1-1）

E-mail of corresponding author: ki-nakamura@sakura-rubber.co.jp
} 


$$
Q=2.085 d_{1}^{2} \sqrt{P_{N}}
$$

これは非圧縮性流体かつ定常流におけるベルヌーイの定理からの導出であり，ノズル出口断面中心の流速とピトー管 計測点に適用し，ノズル内部の流体粘性による影響を踏まえ導出されたものである(東京消防機器研究会，2015). この ため省令で規定される動力消防ポンプ性能評価のための流量推定に，ノズル圧力 $P_{N}$ の值は必要不可欠である.

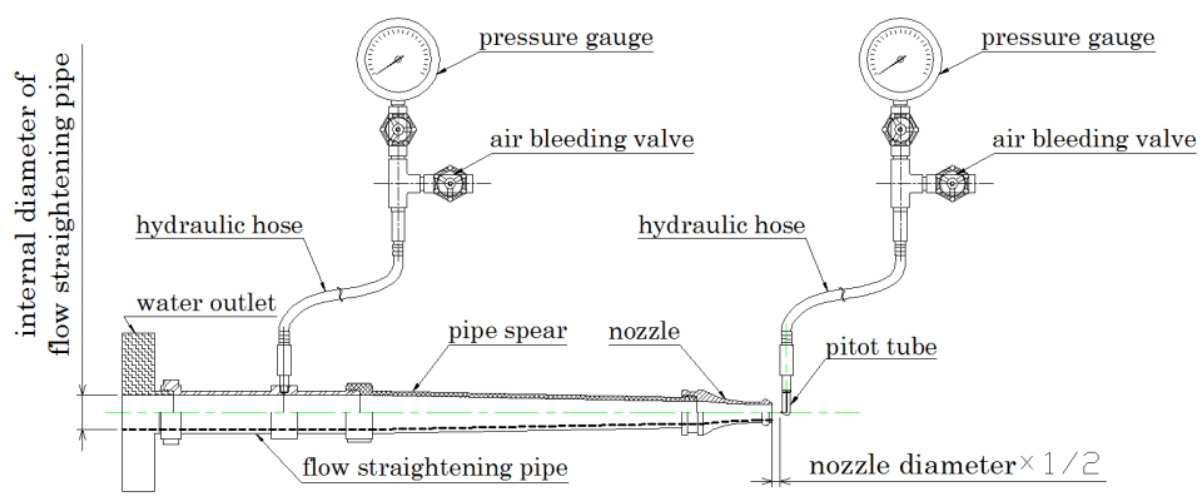

Fig.1 Example of equipment for measuring static pressure and nozzle pressure. Flow straightening pipe, pipe spear and nozzle are attached to a discharge outlet of fire engine by this order. Static pressure is perpendicular pressure on flow in the flow straightening pipe. Nozzle pressure is the total pressure at the half distance of nozzle diameter from the nozzle exit on the centerline of flow. Note : The two pressure gauges was installed at the same height as the central axis of the nozzle model.

従前の消防ポンプ性能評価における整流筒内径は65 mmが主流である.この場合，ノズル口径 $d_{1}$ が既知であれば，上 流側の静圧 $P_{0}$ を計測するのみで, ノズル圧力 $P_{N}$ を予測するための関係が次式 (以下「加算式」と呼ぶ) で与えられる.

$$
P_{N}=P_{0}+P_{A}
$$

ただし対応するパラメータは表1(吉谷機械製作所, Private communication)に整理され， $P_{N}$ から $P_{0}$ を減じた值を $P_{A}$ と定 義している．表1の関係は経験的に知られていることで，実際の性能評価の現場で多く活用され，多くの実験からデー タベースとして整理されたものである. この方法の優れている点は静圧のみの計測で放水性能が算出でき，ピト一管に よる計測誤差を回避できることにある. 一方, 実験データを基にしているため, 整流筒内径65 mm以外には適用できな い. 昨今の動力消防ポンプの大容量化に伴い，性能評価に使用する整流筒内径は，従来の65 mmから，一回り大きい 75 mmが使用され，扱うレイノルズ数の桁の範囲も，105から106へと推移している. この口径に対する同様のデータ ベースが必要となるが, 高レイノルズ数であることに加え, 現システムが従前の65 mmを基本としたものであることか ら，75 mmのデータベース作成は現状困難である. また65 mmのデータベース作成時に議論されたであろう理論的背 景および工学的考察は資料が散失し確認できない. 整流筒内径75 mmにも適用可能で, 加算式に代わる容易なノズル圧 力の推定方法が必要とされている.

\begin{tabular}{|c|c|c|c|c|c|c|c|c|c|c|c|c|c|}
\hline \multirow{2}{*}{$\begin{array}{c}P_{A} \\
{[\mathrm{MPa}]}\end{array}$} & \multicolumn{13}{|c|}{$d_{1}[\mathrm{~mm}]$} \\
\hline & 43.5 & 42.25 & \begin{tabular}{l|l}
5 & 41
\end{tabular} & & 9.5 & 5.5 & 33.5 & 30.5 & 27.5 & 24.5 & 21.5 & 18.5 & 16.5 \\
\hline 0.00 & 0.000 & & .000 & 0.000 & 0.000 & 0.000 & \begin{tabular}{|l|l|}
0 & 0.000
\end{tabular} & $\begin{array}{l}0.000 \\
\end{array}$ & \begin{tabular}{|l|l|}
0 & 0.000 \\
\end{tabular} & \begin{tabular}{l|l}
0 & 0.000 \\
\end{tabular} & 0.000 & & .000 \\
\hline 0,01 & 0.075 & & .085 & 0.095 & 0.125 & 0.175 & \begin{tabular}{|l|l|}
5 & 0.265 \\
\end{tabular} & 0.395 & \begin{tabular}{|l|l|}
5 & 0.615 \\
\end{tabular} & \begin{tabular}{|l|l|}
5 & 1.005 \\
\end{tabular} & 1.765 & & .385 \\
\hline $\begin{array}{l}0.01 \\
0.02\end{array}$ & 0.09 & & .115 & 0.125 & 0.175 & 0.245 & \begin{tabular}{|l|l|}
5 & 0.355 \\
\end{tabular} & 0.545 & \begin{tabular}{|l|l|}
5 & 0.845 \\
\end{tabular} & 1.395 & 2.455 & & .735 \\
\hline$\frac{0.02}{0.03}$ & 0.14 & & .175 & 0.185 & 0.255 & 0.375 & \begin{tabular}{|l|l|}
5 & 0.545 \\
\end{tabular} & 0.815 & \begin{tabular}{|l|l|}
5 & 1.285 \\
\end{tabular} & \begin{tabular}{|l|l|}
5 & 2.115 \\
\end{tabular} & 3.725 & & \\
\hline$\frac{0.03}{0.04}$ & 0.205 & & 245 & 0.255 & 0.365 & 0.525 & \begin{tabular}{|l|l|}
5 & 0.765 \\
\end{tabular} & \begin{tabular}{|l|l|} 
& 1.155 \\
\end{tabular} & \begin{tabular}{l|l}
5 & 1.815 \\
\end{tabular} & \begin{tabular}{l|l|}
5 & 2.985 \\
\end{tabular} & 5.265 & & \\
\hline$\frac{0.04}{0.05}$ & 0.25 & & 295 & 0.315 & 0.445 & 0.635 & 50.935 & 1.415 & \begin{tabular}{|l|l|}
5 & 2.215 \\
\end{tabular} & \begin{tabular}{|l|l|}
5 & 3.645 \\
\end{tabular} & & & \\
\hline$\frac{0.05}{0.06}$ & 0.305 & & 355 & 0.375 & 0.535 & 0.765 & $\begin{array}{l}5 \\
\end{array}$ & 1.695 & \begin{tabular}{l|l}
5 & 2.655 \\
\end{tabular} & \begin{tabular}{|l|l|}
5 & 4.385 \\
\end{tabular} & & & \\
\hline$\frac{0.00}{0.07}$ & 0.39 & & .465 & 0.495 & 0.695 & 0.985 & \begin{tabular}{|l|l|}
5 & 1.445 \\
\end{tabular} & 2.175 & \begin{tabular}{|l|l|}
5 & 3.395 \\
\end{tabular} & & & & \\
\hline$\frac{0.07}{0.08}$ & 0.49 & & .585 & 0.615 & 0.865 & 1.235 & \begin{tabular}{|l|l|}
5 & 1.805 \\
\end{tabular} & 2.705 & \begin{tabular}{|l|l|}
5 & 4.245 \\
\end{tabular} & & & & \\
\hline $\begin{array}{l}0.08 \\
0.09\end{array}$ & 0.56 & & 665 & 0.705 & 0.995 & .415 & \begin{tabular}{|l|l|}
5 & 2.055 \\
\end{tabular} & 3.105 & & & & & \\
\hline$\frac{0.09}{0.10}$ & 0.60 & & .705 & 0.745 & 1.055 & .505 & \begin{tabular}{|l|l|}
5 & 2.195 \\
\end{tabular} & & & & & & \\
\hline 0.10 & 0.685 & & 805 & 0.845 & 1.195 & 1.695 & \begin{tabular}{|l|l|}
5 & 2.485 \\
\end{tabular} & & & & & & \\
\hline 0.11 & 0.72 & & 845 & 0.895 & 1.255 & 1.795 & & & & & & & \\
\hline 0.12 & 0.75 & & 895 & 0.945 & 1.325 & .895 & & & & & & & \\
\hline$\frac{0.13}{0.14}$ & 0.85 & & .005 & 1.055 & 1.485 & 2.115 & & & & & & & \\
\hline 0.14 & 0.945 & & .115 & 1.175 & 1.645 & 2.355 & & & & $P_{0}[\mathrm{M}$ & $\mathrm{MPa}$ & & \\
\hline & 0.995 & & .165 & 1.235 & 1.735 & 2.465 & & & & & & & \\
\hline 0.10 & 1.035 & & 225 & 1.295 & 1.815 & 2.585 & & & & & & & \\
\hline & 1.08 & & 285 & 1.355 & 1.895 & 2.705 & & & & & & & \\
\hline 0.18 & 1.14 & & 355 & 1.425 & 1.995 & 2.845 & & & & & & & \\
\hline
\end{tabular}

Table 1 Addition level from static pressure for nozzle diameter. 
消防用ノズルにおける上流側静圧からノズル圧力を算出する問題に対し，古くは(村上，片山，1965a，1965b)でも論 じられているが，その適用範囲は上述の加算式よりも狭い. 近年では高レイノルズ数の流れに対して実験的で精力的な 評価(古市，寺尾，2014，和田他，2015)が進められているものの，様々な課題は残されたままであり，また計算機を使 用した手法として，览密な DNS などを用いる可能性，たとえば(Eggels et al., 1994, Khoury et al., 2013)もあるが，高レイ ノルズ数であること，また，実運用の観点から考えても費用対効果はよくない.

以上の背景から，本論文は村上ら(村上，片山，1965a，1965b)の次報として，(1)ノズル圧力（動圧）の実験值と経験 的に使用されてきた加算式を比較し，加算式の妥当性を確認寸る. (2)整流筒内径 $75 \mathrm{~mm}$ に対するノズル上流側の静圧 計測によるノズル圧力推定のため, 新しい推定式を導入, 整流筒内径 $65 \mathrm{~mm}$ における加算式の代替となることを示す. (3)整流筒内径 $75 \mathrm{~mm}$ における実験值と推定式を比較し, 推定式が動力消防ポンプの大容量化にともなう性能評価に対 応し，安全側に評価される保守的かつ容易なノズル圧力の推定方法であることを提案する.

\section{2. 定 義·記 号}

図1における「整流筒十管鎗十ノズル」を便宜上，ノズルモデルと呼び，図2はその模式図である.ノズルモデルの内 部流体は非珐縮性流体かつ定常流を考える．また本論分での圧力は全てゲージ圧を表す。

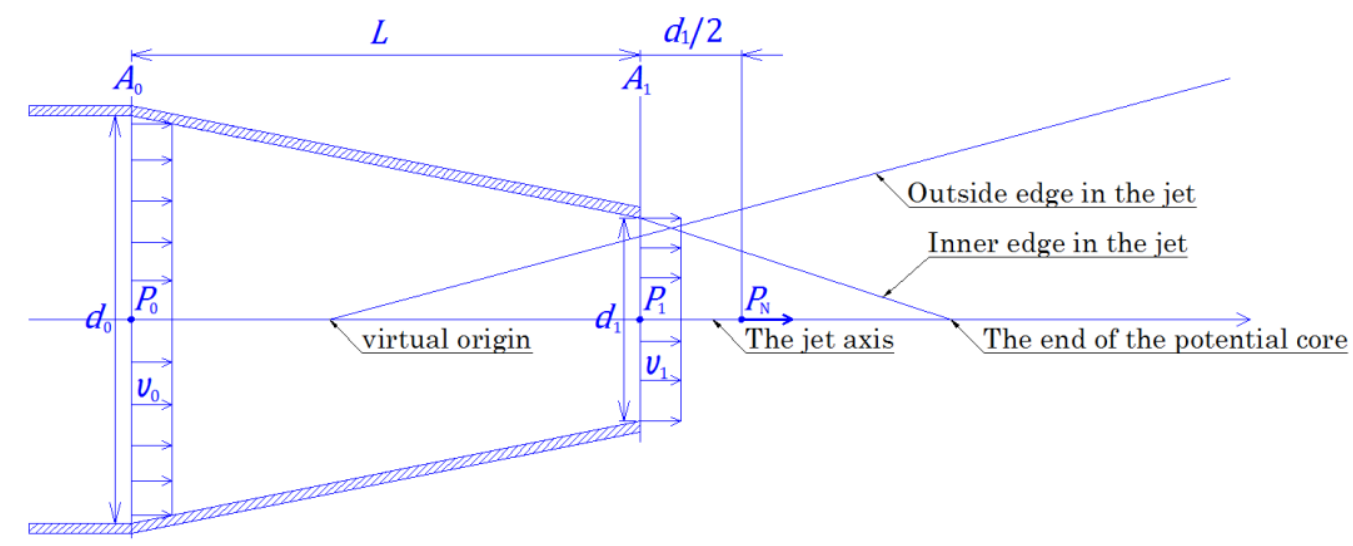

Fig.2 Definition of each symbol and schematic view of nozzle model. There is a domain called potential core where the velocity profile is uniform. The potential core ends at the point where the inner edge of the jet intersects the jet axis (Rajaratnam, 1983).

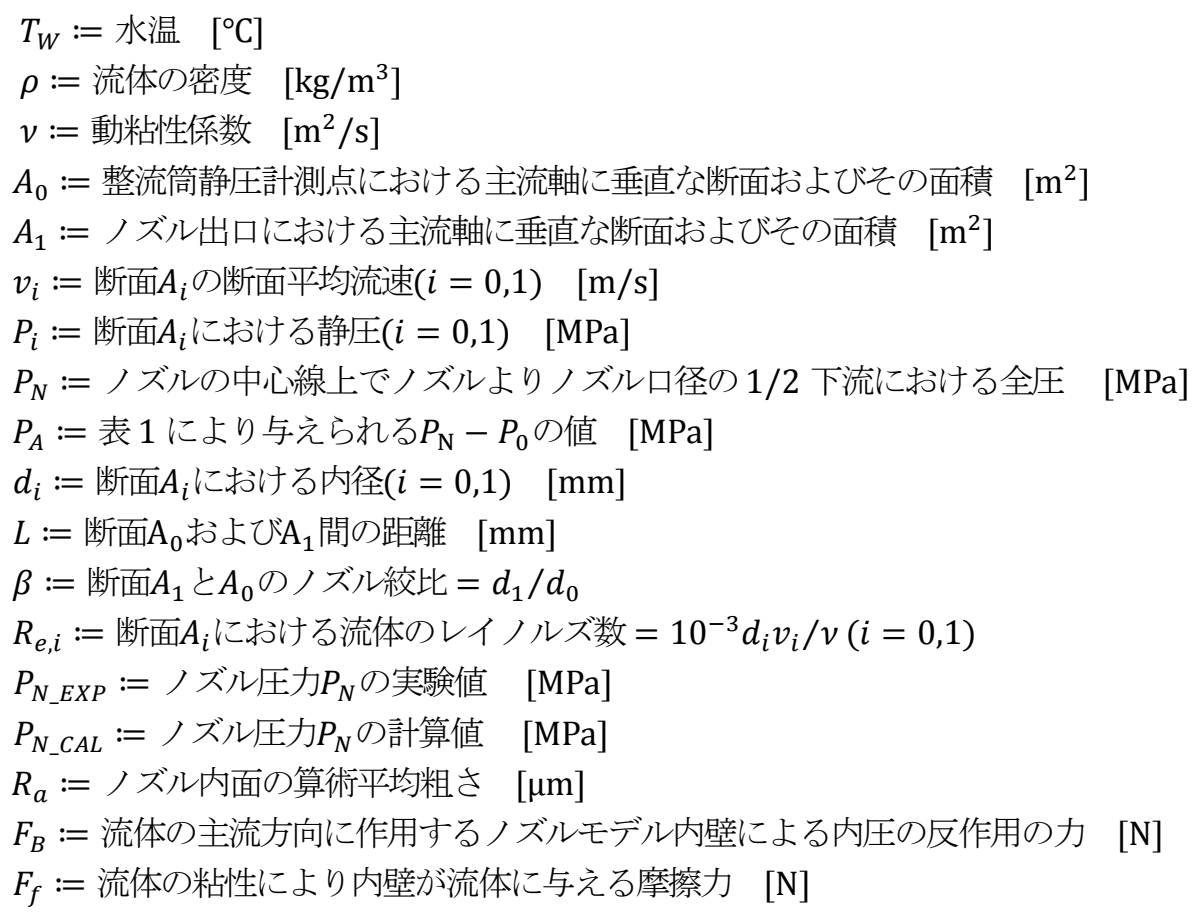




\section{3. 実 験}

\section{$3 \cdot 1$ 実験方法}

本報告で導入する推定式との比較のため，実際の性能評価と同様の環境下で，整流筒内径65 mmおよび75 mmを用 いて，口径の異なる複数の消防用ノズルに対する放水実験を行った.ノズルの内面粗さは表面粗さ測定機 (ミツトヨ SJ210）で計測し，流体力学的に滑らかなものを使用した. 整流筒内径により 2 つのグループに類別し，表 $2 に$ 使用したノ ズルモデルの仕様を示す．A群に 3000 L/min級，B群には5000 L/min級の消防ポンプ車を用意した.

Table 2 Nozzle models of experiment.

\begin{tabular}{|c|c|c|c|c|c|c|c|c|c|c|c|c|c|c|c|c|}
\hline Classification & \multicolumn{10}{|c|}{ group A } & \multicolumn{10}{c|}{ group B } \\
\hline$d_{0}[\mathrm{~mm}]$ & \multicolumn{10}{|c|}{65} & \multicolumn{10}{c|}{75} \\
\hline$d_{1}[\mathrm{~mm}]$ & 23 & 26 & 27 & 28 & 29 & 30 & 44 & 46 & 48 & 50 & 52 & 54 & 56 & 58 & 60 & 63 \\
\hline$\beta$ & 0.35 & 0.40 & 0.42 & 0.43 & 0.45 & 0.46 & 0.68 & 0.71 & 0.74 & 0.77 & 0.80 & 0.83 & 0.86 & 0.89 & 0.92 & 0.97 \\
\hline$L[\mathrm{~mm}]$ & \multicolumn{10}{|c|}{875} \\
\hline$R_{a}[\mathrm{\mu m}]$ & 0.81 & 1.84 & 1.55 & 0.82 & 1.04 & 0.84 & 1.56 & 0.83 & 0.78 & 1.12 & 1.27 & 0.66 & 0.96 & - & 0.63 & 2.20 \\
\hline
\end{tabular}

消防ポンプ車を水槽の直近に配置, 取水に吸管を使用し，揚程は1.0 mとした. 車両側面の放水口の一つに図 1 のノズ ルモデルを接続し，表3に示寸条件のもとポンプ回転を変化させた．整流筒から垂直に立ち上げたホースの先に取付け た圧力計で静圧 $P_{0}$, ノズル先では内径 $1.3 \mathrm{~mm}$ のピトー管の先に取付けた圧力計により，ノズル圧力 $P_{N}$ を計測した. た だし圧力計はブルトン管式精密圧力計 (長野計器, 型式 GP20-241, 圧力レンジ0〜3.5 MPa, 最小目盛0.01 MPa, 精度: $\pm 0.25 \%$ F. S.）を使用し，圧力計の手前に設置したバルブを絞ることで針の振動を圧力計の精度以下に抑え，中央值を 計測した. また 2 台の圧力計の設置高さをノズルモデル中心軸高さと同一とした. 図3は B 群の資機材配置例である.

Table 3 Experimental conditions.

\begin{tabular}{|c|c|c|c|c|c|}
\hline pomp class & pomp type & Power source & suction hose & suction head & $T_{W}$ \\
\hline $3000[\mathrm{~L} / \mathrm{min}]$ & $\begin{array}{c}\text { balance turbine } \\
2 \text { impeller steps }\end{array}$ & engine $150[\mathrm{PS}]$ & $75[\mathrm{~mm}] \times 2$ lines & $1.0[\mathrm{~m}]$ & $20\left[{ }^{\circ} \mathrm{C}\right]$ \\
\hline $5000[\mathrm{~L} / \mathrm{min}]$ & $\begin{array}{l}\text { balance turbine } \\
2 \text { impeller steps }\end{array}$ & engine $320[\mathrm{PS}]$ & $100[\mathrm{~mm}] \times 3$ lines & $1.0[\mathrm{~m}]$ & $30\left[{ }^{\circ} \mathrm{C}\right]$ \\
\hline
\end{tabular}

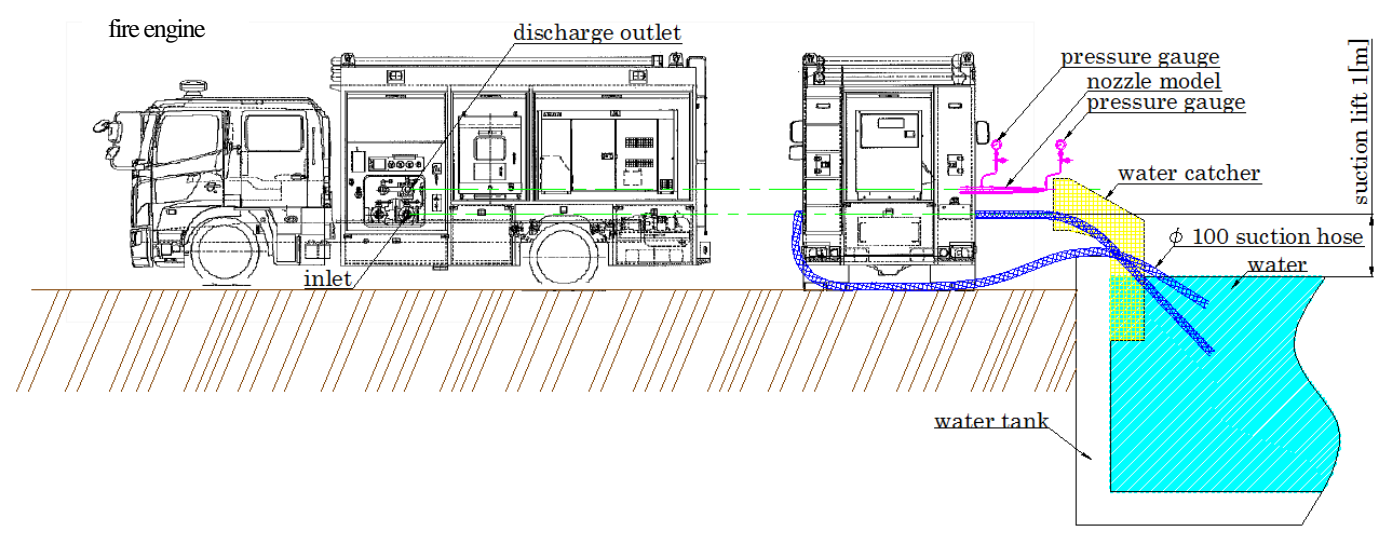

Fig.3 Example of fire engine equipment arrangement of $5000 \mathrm{~L} / \mathrm{min}$ class. Two pressure gauges are Bourdon tubes. The two pressure gauges was installed at the same height as the central axis of the nozzle model. Water in the tank was primed to the main pump by vacuum pump using three $\Phi 100$ suction hoses. The vacuum pump was stopped simultaneously with pressurization to water by the main pump. Pressurized water was water discharged from the nozzle model attached to water discharge outlet of the fire engine, and it was returned from water catcher to the water tank.

\section{$3 \cdot 2$ 実験結果と理論式}

損失の無い理想的な場合, 縮流部のある円管内を流れるノズル流量計の原理で知られるように, ベルヌーイの定理お よび連続の式からノズル出口断面平均流速が断面 $A_{0}$ の静圧により算出される. ポテンシャルコアの長さは約 $5 d_{1}$ あり, ノズル圧力の計測点がポテンシャルコアの中にある(ラジャラトナム，1983)ことから，ノズル出口断面平均流速による

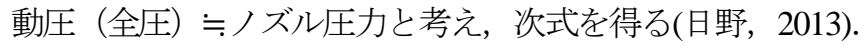




$$
P_{N}=\frac{1}{1-\beta^{4}} P_{0}
$$

横軸を $\beta$, 縦軸には $P_{A} / P_{0}$ に相当寸るノズル圧力と静圧の差を無次元化した $P_{N} の P_{0}$ からの超過比 $\left(P_{N}-P_{0}\right) / P_{0}$ を取り, 式(3)（以下これを「理論式」と呼ぶ）の分布を実験值と共に，A群を図4(a)，B 群を図4(b)に示した. また図4(a)には $\mathrm{A}$ 群の実験で計測した $P_{0}$ に対し，加算式により算出される $P_{N}$ の $P_{0}$ からの超過比 $\left(P_{N}-P_{0}\right) / P_{0}$ を重ねた.
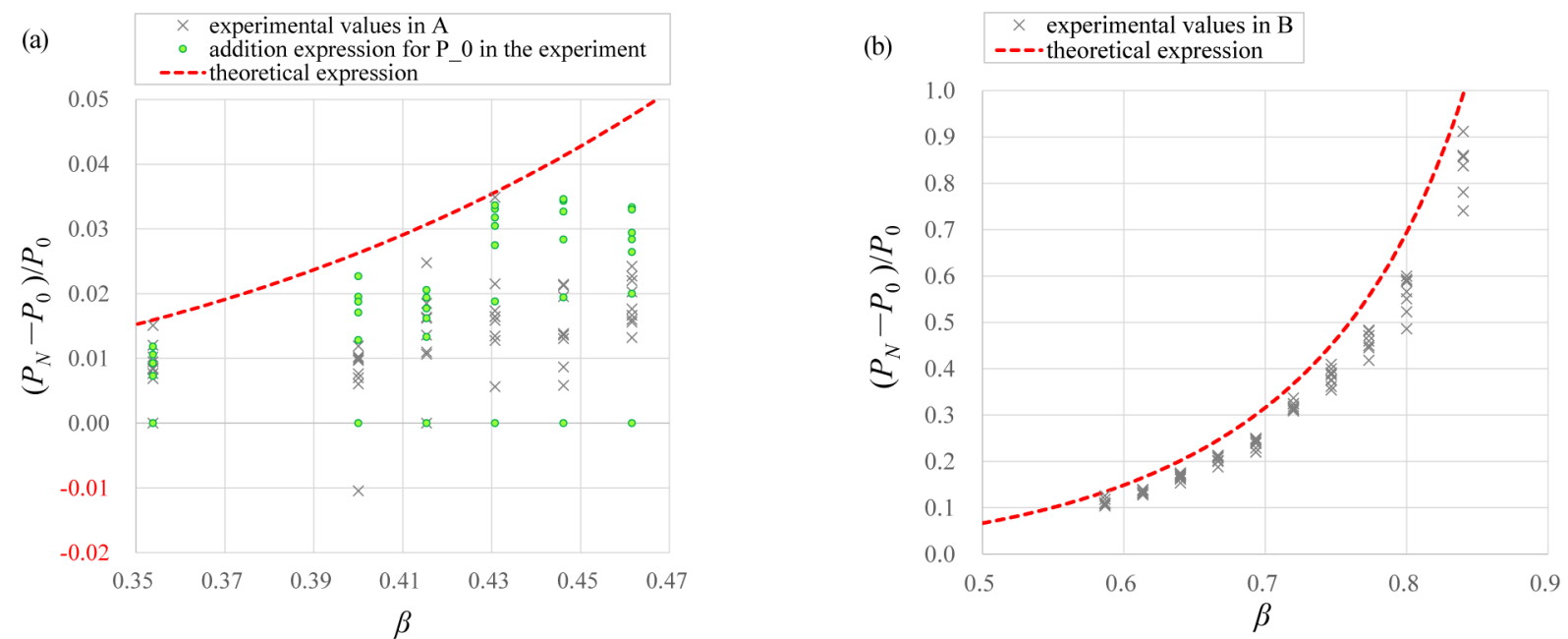

Fig.4 Vertical axis is ratio of excess from static pressure of upstream side. Horizontal axis is $\beta$. (a) : Comparison between theoretical expression, addition expression for $P_{0}$ in the experiment and experimental values in A. Distribution of addition expression in $\mathrm{A}$ was similar to distribution of experimental values. (b) : Comparison between theoretical expression and experimental values in B. Theoretical expression drew the curve that is the envelope of the upper limit of experimental values. Theoretical expression was excessive for experimental values.

理論式はノズルモデルの形状や摩擦損失を考慮していない分，図4(a)，(b)において実験值の上限を包絡する曲線を 描き，実験值に対して過分であったＡ群に対する加算式の分布は，実験值の分布に類似した。

実験で計測したノズル圧力 $P_{N}$ をレイノルズ数に置き換え図 5 に示寸. A 群のレイノルズ数範囲は $4.5 \times 10^{5} \sim 1.7 \times$ $10^{6}$ であり, B 群のレイノルズ数範囲は1.7 × 106 $3.1 \times 10^{6}$ であった. ただしレイノルズ数は, 計測したノズル圧力 ノズル出口断面平均流速による動圧（全圧）と考え，水温を踏まえた水の密度および動粘性係数から算出している.

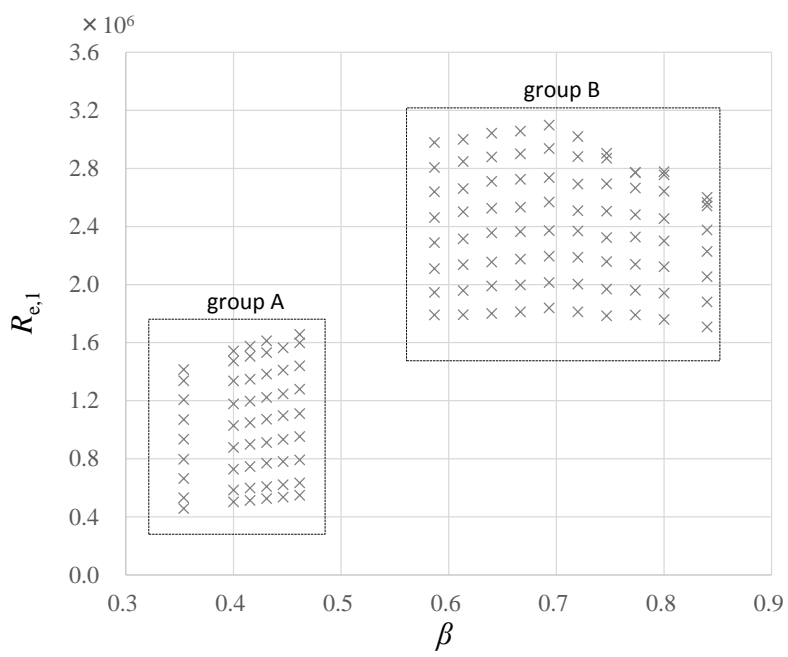

Fig.5 Reynolds number distribution at nozzle outlet of experimental values. Vertical axis is $R_{\mathrm{e}, 1}$. Horizontal axis is $\beta$.

実験值と加算式または理論式との差異を評価するため, 縦軸に実験值の各式からの超過比 $\left(P_{\mathrm{N}_{-} \mathrm{EXP}}-P_{\mathrm{N}_{-} \mathrm{CAL}}\right) / P_{\mathrm{N}_{-} \mathrm{CAL}}$ を取り，横軸を $\beta$ とし，実験值の各式に対する超過比の分布を図6(a)に示す．また横軸を $R_{e, 1}$ とし，レイノルズ数の側 面から観察したものを図6(b)に示寸，ただし $P_{\mathrm{N}_{-} \mathrm{CAL}}$ は加算式であれば式(2), 理論式であれば式(3)で与えられる. 

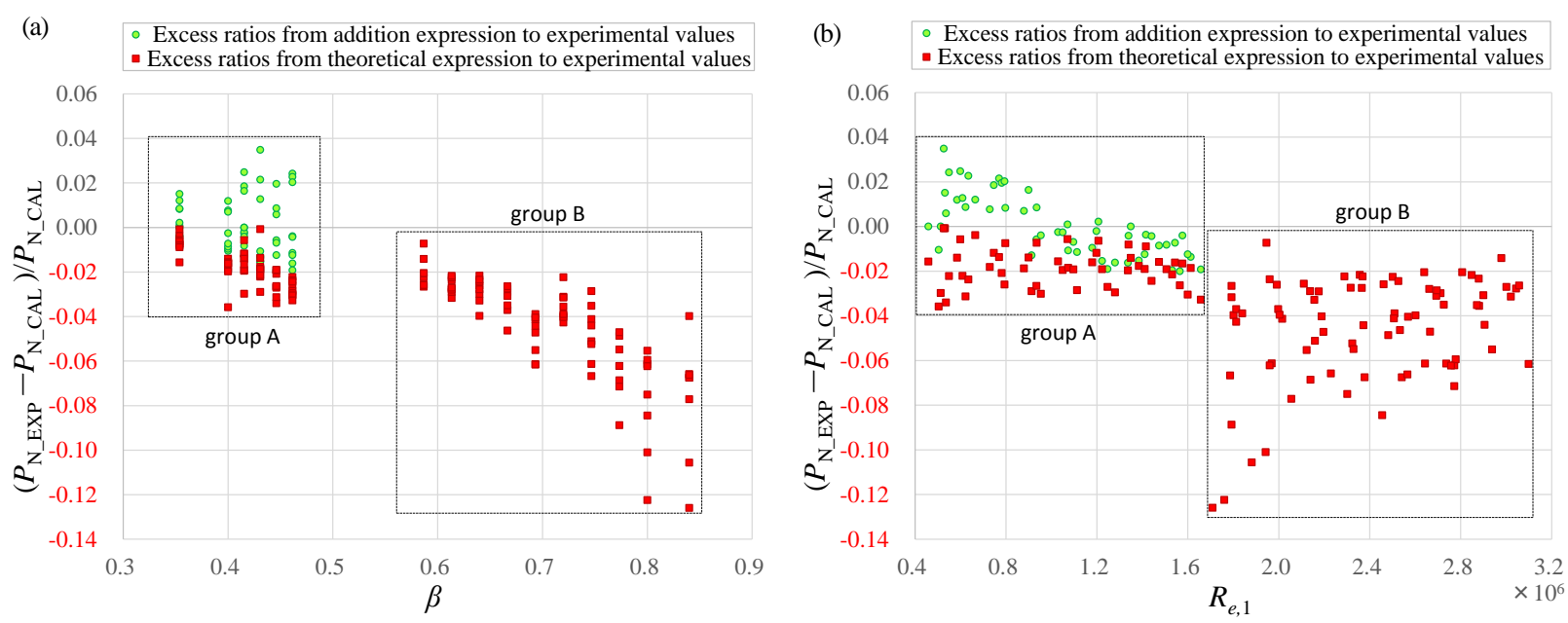

Fig.6 Comparison between theoretical expression, addition expression for $P_{0}$ in the experiment and experimental values. Vertical axis is excess ratios from addition expression (or theoretical expression) to experimental values. Horizontal axis is $\beta$ (Fig.(a)) or $R_{\mathrm{e}, 1}$ (Fig.(b)). Excess ratios from addition expression to experimental values were less than $\pm 4 \%$ at $90 \%$ of confidence level.

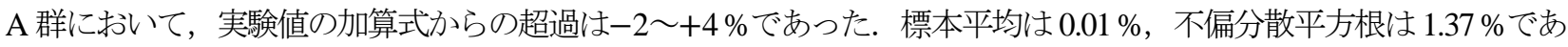
り，チェビシェフの不等式により，統計的に $90 \%$ の確率（以下「信頼率 $90 \%$ 」表現）で加算式からの超過は土4\%以 下となる，一方，実験值の理論式からの超過はー4〜0\%であり，統計的に信頼率 $90 \%$ で実験值の理論式からの超過は -5〜+1\%であった. 理論式は実験值をよく近似しているが摩擦損失を考慮していないため過分である.

B 群において，実験值の理論式からの超過は-13〜-1\%であり，統計的に信頼率 $90 \%$ で実験值の理論式からの超過 は-12〜+3\%であった. 理論式は実験值に対して過分であり差異が大きくなった. 特にノズル絞比である $\beta$ が大きくか つレイノルズ数 $R_{e, 1}$ が小さい場合に実験值との差異がより大きくなる傾向を示した. $\beta$ が小さいほどノズルモデル内部 流体における境界層は壁面曲率の影響を受けて減少し摩擦損失は小さくなり, 実験值と摩擦損失を考慮していない理論 式の差異は減少する. またレイノルズ数 $R_{e, 1}$ が小さいほど摩擦損失係数は大きくなり, 摩擦損失を考慮していない理論 式と実験值の差異は増大する. これら 2 つ要素が重なると, 実験值と理論式の差異はより大きくなると推測される.

上述の通り，加算式は $\mathrm{A}$ 群の実験值をよく近似したが B 群には対応しない. B 群にも適用可能かつ安全側に評価さ れ，保守的で容易なノズル圧力の推定方法が要求される.

\section{4. ノズル圧力の推定}

断面 $A_{0}$ と断面 $A_{1}$ との間の流体に作用する力は, 圧力差による力と, 内壁が流体に与える力がある. 内壁が流体に与え る力には, 摩擦力 $F_{f}$ と内壁近傍の静圧が内壁に作用する力の反作用 $F_{B}$ がある. 運動量理論より $10^{6} A_{0} P_{0}-10^{6} A_{1} P_{1}+$ $F_{B}+F_{f}=\rho A_{1} v_{1}\left(v_{1}-v_{0}\right)$ が成り立つ. ここでは摩擦力を 0 と仮定する $\left(F_{f}=0\right)$. またノズルモデルは先細りのテ 一パ形状のため下流に向かって静圧は低下するが, 静圧を一様に $P_{0}$ と仮定し, 内壁に作用する静圧の反作用を考える.

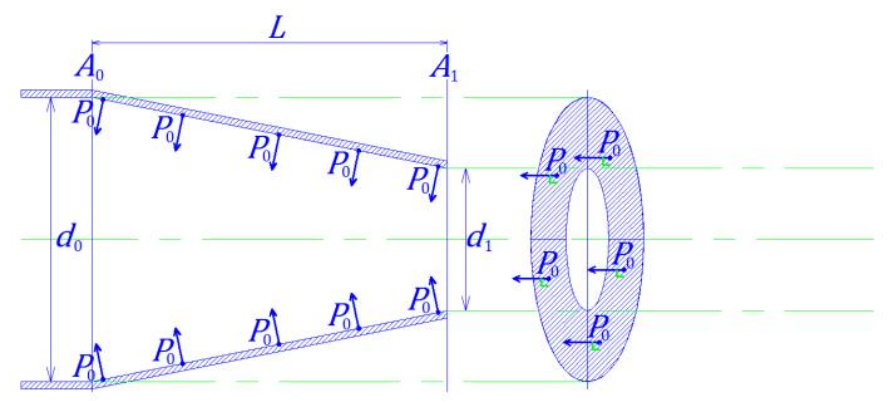

Fig.7 The static pressure in nozzle model decreases toward the downstream due to the taper shape, but the static pressure is assumed to be $P_{0}$ uniformly, and the reaction of the static pressure acting on the inner wall is considered. The force exerted by the inner wall of nozzle model to the main flow direction of fluid is the product of the toroidal area obtained by projecting the inner wall on a plane perpendicular to the main flow direction and the static pressure. 
ノズルモデルを単純な円錐台側面形状とすれば，内壁が流体の主流方向に与える力は，主流方向に垂直な平面に内壁 を射影したドーナツ状の面積に，静圧一 $P_{0}$ を乗じた值（図7）であり, $F_{B}=-10^{6} P_{0}\left(A_{0}-A_{1}\right)$ と書ける. 運動量理論 の式にこれを代入し, $10^{6} P_{0}=\rho v_{1}\left(v_{1}-v_{0}\right)$ を得る. この式に連続の式とベルヌーイの定理を適用し，ノズル圧力の計 測点がポテンシャルコアの中にあることからノズル出口断面平均流速による動圧（全圧）〕ノズル圧力と考え

$$
P_{N}=\frac{1}{2}\left(1-\beta^{2}+\frac{1}{1-\beta^{2}}\right) P_{0}
$$

が導出される. 横軸を $\beta$, 縦軸には $P_{N} の P_{0}$ からの超過比 $\left(P_{N}-P_{0}\right) / P_{0} を$ 取り, 式(4)（以下これを「推定式」と呼ぶ）の 分布を実験值と共に図8に示寸. 推定式は $\mathrm{A}$ 群および $\mathrm{B}$ 群における実験值の回帰曲線 (4 次の多項式近似) に近似した.

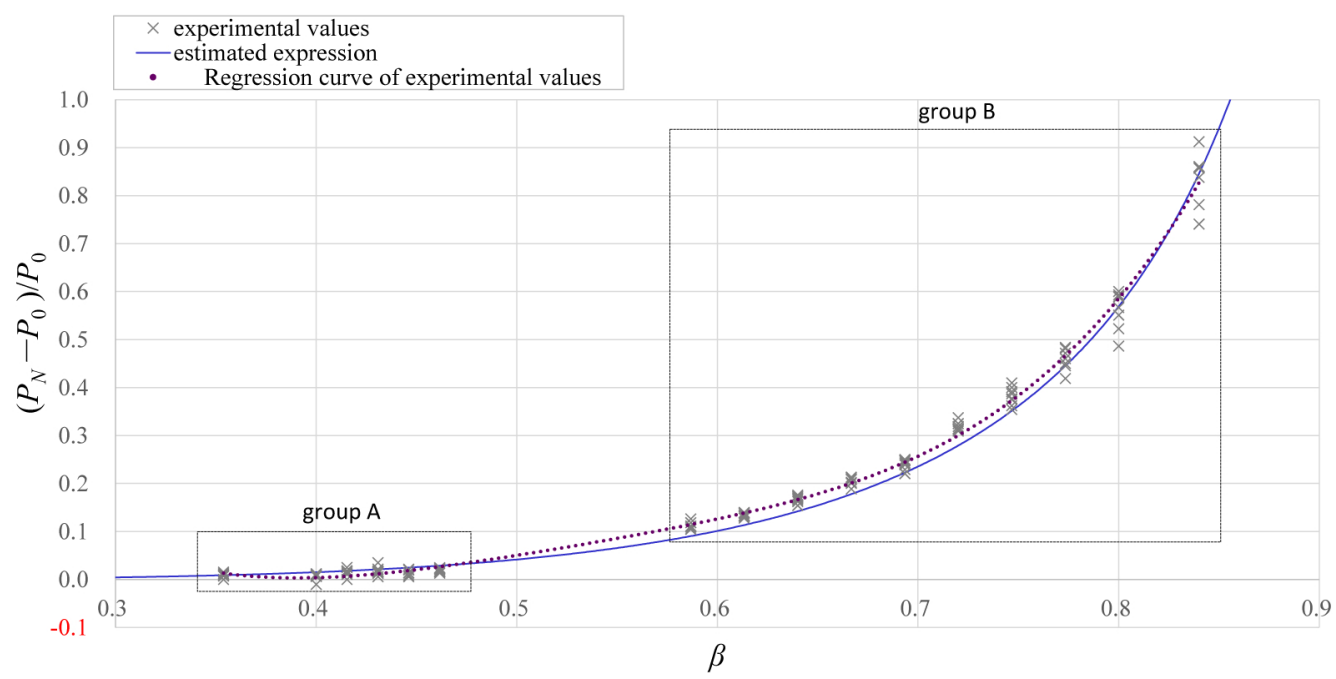

Fig.8 Estimated expression was similar to the regression curve (the fourth multinomial expression approximation) of experimental values.

図9は加算式, 理論式および推定式の関係をみるため, 横軸を $\beta$, 縦軸には $P_{N} の P_{0}$ からの超過比 $\left(P_{N}-P_{0}\right) / P_{0}$ を取り, 各式の分布を重ねた. 加算式は階段状の分布を示し, 理論式はその階段状の頂点を結ぶ包絡線であり, 推定式は加算式 の階段状分布の中央を通る曲線として表れた.

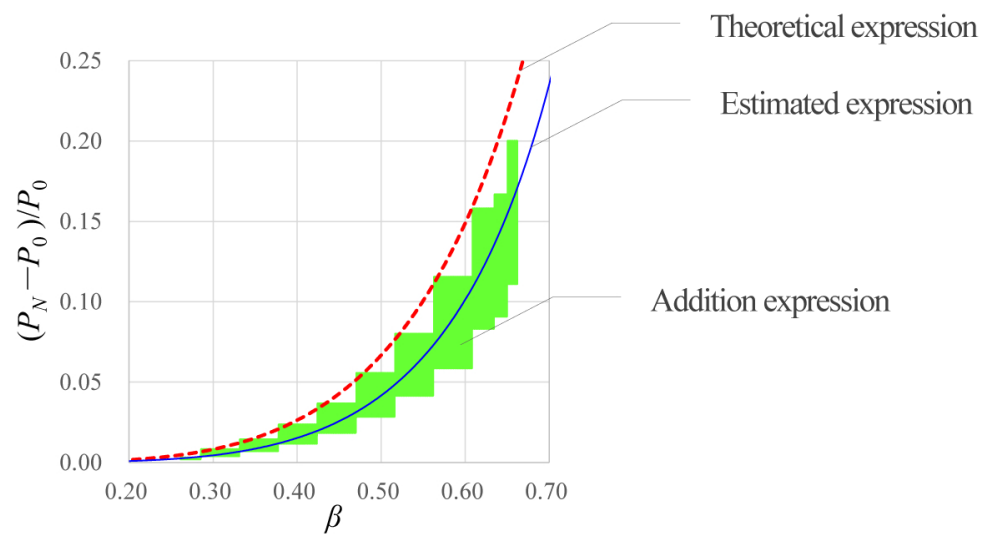

Fig.9 Distribution of addition expression, theoretical expression and estimation expression. Distribution of addition expression was a stepped graph. Distribution of theoretical expression was an envelope curve to link stepped top of addition expression. Distribution of estimated expression was a curve via the center of stepped distribution of addition expression.

推定式と実験值の差異を定量的にみるため, 縦軸に実験值の推定式からの超過比 $\left(P_{\mathrm{N}_{-} \mathrm{EXP}}-P_{\mathrm{N}_{-} \mathrm{CAL}}\right) / P_{\mathrm{N}_{-} \mathrm{CAL}}$ を取り, 横軸を $\beta$ とし，実験值の推定式に対する超過比の分布を図10(a)に示す。ここで $P_{N_{-} C A L}$ は推定式を表し，式(4)で与えら れる. また横軸を $R_{e, 1}$ とし, レイノルズ数の側面から観察したものを図10(b)に示す. 図10は実験值のばらつきに振ら れ，当然のことながら図6に類似した分布となっている. 
(a)

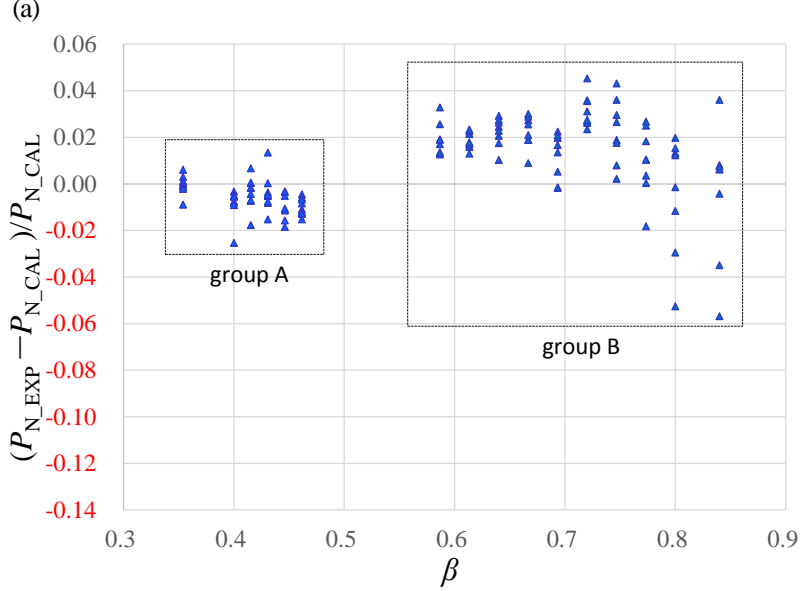

(b)

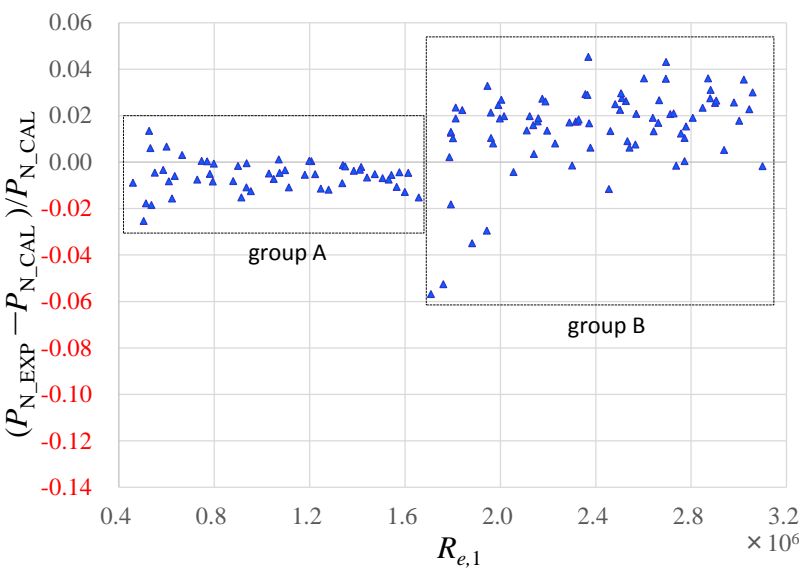

Fig.10 Comparison between estimated expression and experimental values. Vertical axis is excess ratios from estimated expression to experimental values. Horizontal axis is $\beta$ (Fig.(a)) or $R_{\mathrm{e}, 1}$ (Fig.(b)). Excess ratios from estimated expression to experimental values in A were from -3 to $+2 \%$ at $90 \%$ of confidence level. Excess ratios from estimated expression to experimental values in B were from -4 to $+7 \%$ at $90 \%$ of confidence level. When $\beta$ level in particular was less than 0.8 , excess ratios from estimated expression to experimental values in B were from -1 to $+5 \%$ at $90 \%$ of confidence level.

A 群において，実験值の推定式からの超過はー3〜+2\%であり，統計的に信頼率 $90 \%$ で実験值の推定式からの超過は -3〜+2\%であった. 一方 B 群において，実験值の推定式からの超過は-6〜+5\%であり，統計的に信頼率 $90 \%$ \%実験 值の推定式からの超過は-4〜+7\%であった. 特に $\beta$ 值が 0.8 未満の場合，実験值の推定式からの超過はー2〜+5\%であ り，統計的に信頼率 $90 \%$ で実験值の推定式からの超過は-1〜+5\%であった.

推定式は実験值をよく近似し， B 群では $\beta$ 值が 0.8 未満の場合，安全側に評価される保守的な近似であることを示し た. 逆に $\beta$ 值が 0.8 以上かつレイノルズ数が $2 \times 10^{6}$ 以下では実験值との差異が大きくなり，実験值に対して過分になる 場合が確認された．推定式の適用範囲には注意が必要であり，その評価は今後の課題である.

\section{5. 結言}

動力消防ポンプにおける放水量の大容量化に伴い，従前の加算式に代わる容易なノズル圧力の推定方法が必要 とされている. 村上ら(村上，片山，1965a，1965b)の報告を踏まえ，整流筒内径65 mmのノズルモデルとそれに続く整 流筒内径75 mmのノズルモデルに対する上流側静圧計測によるノズル圧力の推定のため，準解析的に新しい推定式を 提案し, 消防ポンプ車を使用した実験から，加算式および推定式の精度を評価した. 以下結果を示す。

（1）整流筒内径65 mmのノズルモデルに対し，従前の加算式は土4\%の精度（信頼率 $90 \%$ \% ) で実験值に近似するこ とを確認した.

（2）新しく導入した推定式は，実験值の回帰曲線（4次の多項式近似）に近似することを示した.ノズル圧力の上流 側静圧からの差の比を縦軸とし，ノズル絞り比を横軸としたグラフ (図9)において, 加算式は階段状分布となり, 推定式はその中央を通る加算式の代表值であることを確認した.

（3）整流筒内径65 mmのノズルモデルに対し，推定式は－3～+2 \%の精度（信頼率 $90 \%$ ）で実験值を近似し，従 前の加算式と比べ同等以上の精度であることを確認した。 一方，整流筒内径75 mmのノズルモデルに対し，推定 式は-4 〜 +7\%の精度（信頼率 90\%）で実験值を近似し，推定式の実験值に対する過分側への超過は加算式の精 度と同等であり，かつ安全側に評価される保守的な近似式であることを示した. 特に実用的な範囲であるノズル 絞比 0.8 未満の場合，推定式は-1 〜 +5\%の精度（信頼率 $90 \%$ ）で実験值を近似し，より高い精度で安全側に評 価される保守的な近似式であることを明らかにした。

\section{謝辞}

本論文作成に当たり, 株式会社吉谷機械製作所には長い間幾度にも渡り, 実験のための試験資機材および設備の提供, その他多くの助成を頂いた. また本研究のきっかけにもなった表1に関する貴重なデータの提供と掲載に関し快諾頂い た. ここに深く感謝の意を表したい. 


\section{文献}

Eggels, J.G.M., Unger, F., Weiss, M.H., Westerweel, J., Adrian, R.J., Friedrich, R. and Nieuwstadt, F.T.M., Fully developed turbulent pipe flow: a comparison between direct numerical simulation and experiment, Journal of Fluid Mechanics, Vol. 268 (1994), pp.175-210.

El Khoury, G. K., Schlatter, P., Noorani, A., Fischer, P. F., Brethouwer, G. and Johansson, A. V., Direct numerical simulation of turbulent pipe flow at moderately high Reynolds numbers, Flow Turbulence Combust, Vol.91 (2013), pp.475-495, DOI:10.1007/s10494013-9482-8.

総務省消防庁，消防の動き, No.480 (2011), pp.19-20.

古市紀之, 寺尾吉哉, 広範囲レイノルズ数における管摩擦係数の高精度計測, ながれ, Vol.33 (2014), pp.499-502.

日野幹雄, 流体力学 (2013), pp.68-69, 朝倉書店.

今井秀孝, 測定における不確かさの表現ガイド[GUM]ハンドブック (2018), 日本規格協会.

日本消防検定協会, 消防ポンプ自動車の受託試験細則 (2011), p.11.

川田等, エネルギー, Vol.40, No.1 (2007), pp.122-127, 日本工業新聞社.

総務省, 動力消防ポンプの技術上の規格を定める省令 (昭和 61 年 10 月 15 日自治省令第 24 号), 総務省令, No. 23 (2013)

村上光清, 片山金司, 消防用ノズルの流量係数に関する研究（第 1 報，実験），日本機械学会論文集（第 2 部），Vol. 31 , No. 225 (1965a), pp.769-777.

村上光清, 片山金司, 消防用ノズルの流量係数に関する研究 (第 2 報, 理論的考察)，日本機械学会論文集（第 2 部）, Vol. 31, No. 225 (1965b), pp.778-786.

ラジャラトナム, N., 野村安正 訳, 噴流 (1983), pp.2, 116, 森北出版.

東京消防機器研究会, 新・消防機器便覧 (2015), p.106, 東京法令出版.

和田裕貴, 古市紀之, 寺尾吉哉, 辻義之, 高レイノルズ数円管流における平均速度分布型に関する実験的研究, 日本機械 学論文集, Vol. 81, No. 826(2015), DOI:10.1299/transjsme.15-00091.

吉谷機械製作所，ノズル圧力と送水圧力の関係, Private communication.

\section{References}

Eggels, J.G.M., Unger, F., Weiss, M.H., Westerweel, J., Adrian, R.J., Friedrich, R. and Nieuwstadt, F.T.M., Fully developed turbulent pipe flow: a comparison between direct numerical simulation and experiment, Journal of Fluid Mechanics, Vol. 268 (1994), pp.175-210.

El Khoury, G. K., Schlatter, P., Noorani, A., Fischer, P. F., Brethouwer, G. and Johansson, A. V., Direct numerical simulation of turbulent pipe flow at moderately high Reynolds numbers, Flow Turbulence Combust, Vol.91 (2013), pp.475-495, DOI:10.1007/s10494013-9482-8.

Fire and Disaster Management Agency, Fire department trend, No.480 (2011), pp.19-20 (in Japanese).

Furuichi, N. and Terao, Y., Highly accurate measurement of friction factor for wide range Reynolds number, Nagare, Vol.33 (2014), pp.499-502 (in Japanese).

Hino, M., Fluid dynamics (2013), pp.68-69, Asakura Publishing Co. Ltd., Tokyo (in Japanese).

Imai, H., Guide to the expression of uncertainty in measurement [GUM] handbook (2018), Japanese Standards Association (in Japanese).

Japan fire equipment inspection institute, Regulations of entrusted test of fire engines (2011), p.11 (in Japanese).

Kawada, H., Energy, Vol.40, No.1 (2007), Fuji Sankei Business i., pp.122-127 (in Japanese).

Ministry of International Affairs and Communications (MIC), The ministerial ordinance that establishes technical standards concerning power driven fire pumps, Ordinance of MIC, No.23 (2013) (in Japanese).

Murakami, M. and Katayama, K., Discharge coefficients of fire fighting nozzles : 1st Report, Experimental studies, Transactions of the Japan Society of Mechanical Engineers, Vol.31, No.225 (1965a), pp.769-777 (in Japanese).

Murakami, M. and Katayama, K., Discharge coefficients of fire fighting nozzles : 2nd Report, Theoretical consideration, Transactions of the Japan Society of Mechanical Engineers, Vol.31, No.225 (1965b), pp.778-786 (in Japanese).

Rajaratnam, N., Nomura, Y. trans., Turbulent jets (1983), pp.2, 116, Morikita Publishing (in Japanese).

Tokyo fire equipment association, New handbook of fire equipment (2015), p.106, Tokyo Horei Publishing Co. Ltd., Tokyo (in Japanese).

Wada, Y., Furuichi, N., Terao, Y. and Tsuji, Y., Experimental study on the mean velocity profile in the high Reynolds number turbulent pipe flow, Transactions of the JSME (in Japanese), Vol. 81, No. 826 (2015), DOI:10.1299/transjsme.15-00091.

Yoshitani Kikai-Seisakusyo, Relationship between nozzle pressure and water pressure, Private communication. 